\title{
Mitochondrial calcium uniporter promotes cell proliferation and migration in esophageal cancer
}

\author{
YU MIAO $^{1 *}$, XIAOFEI WANG ${ }^{2 *}$, YAFANG LAI $^{3 *}$, WAN LIN $^{1}$, YING HUANG $^{1}$, \\ HUA YIN $^{1}$, RUIRUI HOU ${ }^{1}$ and FEIXIONG ZHANG ${ }^{1}$
}

\author{
${ }^{1}$ Department of Gastroenterology, General Hospital of Ningxia Medical University, Yinchuan, Ningxia 750000; \\ ${ }^{2}$ Department of Pathology, North China University of Science and Technology Affiliated Hospital, Tangshan, Hebei 063000; \\ ${ }^{3}$ Department of Gastroenterology, Ordos Center Hospital, Ordos, Inner Mongolia 017000, P.R. China
}

Received July 12, 2020; Accepted June 14, 2021

DOI: 10.3892/ol.2021.12947

\begin{abstract}
Increasing evidence has suggested that mitochondrial calcium uniporter (MCU) is involved in various types of cancer. However, its functions remain unclear in esophageal cancer. The aim of the present study was to explore its abnormal expression and clinical implications in esophageal cancer. A total of 110 patients with esophageal cancer were enrolled in the study. Western blotting was performed to examine the protein expression levels of MCU in 8 pairs of esophageal cancer and adjacent normal tissues. Using immunochemistry, a total of 110 esophageal cancer specimens were analyzed to identify the association between MCU expression and clinicopathological features of patients with esophageal cancer. Furthermore, immunofluorescence of MCU was performed. Pearson's correlation analysis was performed between MCU and hypoxia inducible factor (HIF)-1 $\alpha / \mathrm{VEGF} /$ E-cadherin/Vimentin expression based on western blotting. After KYSE-150 and TE-1 cells were treated with the MCU agonist Spermine and a small interfering RNA against MCU (si-MCU), a series of functional assays were performed, including Cell Counting Kit-8, colony formation and Transwell assays. The results revealed that, compared with in adjacent normal tissues, MCU was highly expressed in esophageal cancer tissues. MCU expression was significantly associated with depth of invasion, lymph node metastasis, TNM stage and distant metastasis. Moreover, MCU was significantly correlated with HIF-1 $\alpha /$ VEGF/E-cadherin/Vimentin in esophageal cancer tissues. MCU overexpression promoted
\end{abstract}

Correspondence to: Professor Feixiong Zhang, Department of Gastroenterology, General Hospital of Ningxia Medical University, 804 Shengli South Street, Xingqing, Yinchuan, Ningxia 750000, P.R. China

E-mail: zhangfeixiongmsp@163.com

*Contributed equally

Key words: esophageal cancer, mitochondrial calcium uniporter, metastasis, clinical implications, prognosis
VEGF, MMP2, Vimentin and N-cadherin expression, while it inhibited E-cadherin expression in KYSE-150 and TE-1 cells, and opposite results were observed after transfection with si-MCU. Furthermore, MCU overexpression accelerated the proliferation and migration of KYSE-150 and TE-1 cells. Thus, the current findings suggested that high $\mathrm{MCU}$ expression may participate in cell proliferation, migration and epithelial-mesenchymal transition in esophageal cancer.

\section{Introduction}

Esophageal cancer is one of the most aggressive types of cancer, with high morbidity and mortality worldwide (1). There are two most common histological subtypes: Squamous cell carcinoma and adenocarcinoma. Despite marked improvements of therapies, the overall survival rate of patients with esophageal cancer remains unsatisfactory (2). The poor prognosis of esophageal cancer is attributed to early metastasis (3). Although it has been determined that certain tumor suppressors and oncogenes serve a key role in the occurrence and development of esophageal cancer, it is urgent to identify molecular markers to improve the early diagnosis and prognosis of esophageal cancer (3).

Mitochondrial calcium uniporter (MCU) has been identified as a channel responsible for mitochondrial $\mathrm{Ca}^{2+}$ absorption, which may control cell energy metabolism, ROS production and programmed cell death (4). All cancer tissues exhibit moderate to strong MCU immunostaining (5). Increasing evidence has suggested that MCU serves an important role in cancer metastasis. For example, MCU is highly expressed in metastatic breast cancer and induces cancer metastasis through the Warburg effect (6). MCU-knockdown significantly suppresses cell migration and invasion in triple-negative breast cancer xenografts and decreases tumor growth, lymph node infiltration and lung metastasis (7). MCU is closely associated with metastasis and poor prognosis of patients with hepatocellular carcinoma (8). MCU expression is upregulated in pancreatic cancer tissues compared with in normal tissues, which may be partly mediated by the HINT2 protein (9). Furthermore, MCU is involved in various cellular biological processes. For example, MCU loss hinders cell cycle progression and proliferation (10). However, the expression 
and clinical implications of MCU in esophageal cancer remain unclear. In the present study, the expression levels of MCU were detected in 110 esophageal cancer tissues and its role in esophageal cancer was analyzed.

\section{Materials and methods}

Bioinformatics analysis. The expression levels of MCU were assessed between tumor and normal samples in various types of cancer via Gene Expression Profiling Interactive Analysis (GEPIA; http://gepia2.cancer-pku.cn/\#index). MCU expression between esophageal cancer samples $(\mathrm{n}=182)$ and normal tissues $(\mathrm{n}=286)$ was analyzed in The Cancer Genome Atlas (TCGA; https://portal.gdc.cancer.gov/) normal and GTEx datasets (http://www.gtexportal.org/home/). The differences in MCU expression among different tumor stages were compared in TCGA-Esophageal carcinoma (ESCA) dataset (https://portal.gdc.cancer.gov/projects?filters $=\% 7 \mathrm{~B} \% 22 \mathrm{op} \% 22$ $\% 3 \mathrm{~A} \% 22$ and $\% 22 \% 2 \mathrm{C} \% 22$ content $\% 22 \% 3 \mathrm{~A} \% 5 \mathrm{~B} \% 7 \mathrm{~B} \% 22 \mathrm{op} \%$ $22 \% 3 \mathrm{~A} \% 22$ in $\% 22 \% 2 \mathrm{C} \% 22$ content $\% 22 \% 3 \mathrm{~A} \% 7 \mathrm{~B} \% 22$ field $\% 22$ $\% 3 \mathrm{~A} \% 22$ projects.project_id $\% 22 \% 2 \mathrm{C} \% 22$ value $\% 22 \% 3 \mathrm{~A} \% 5 \mathrm{~B}$ \%22TCGA-ESCA\%22\%5D\%7D\%7D\%5D\%7D).

Patients and specimens. Patients with esophageal cancer who underwent esophagectomy were enrolled in the General Hospital of Ningxia Medical University (Yinchuan, China) between January 2016 to December 2017. The inclusion criteria were as follows: i) Patients were diagnosed with esophageal cancer by at least two experienced pathologists according to histopathology examination; and ii) patients did not receive chemotherapy or radiation therapy before surgery. Finally, a total of 110 patients (mean age, 58.6 years old and age range, 42.6-75.3 years old) with esophageal cancer were included in the study. All tumor and adjacent normal tissues were collected from patients and the distance of the normal tissues was at least $5 \mathrm{~cm}$ from the tumor tissues. All specimens were immediately transferred to liquid nitrogen after surgery, and stored at $-80^{\circ} \mathrm{C}$ until use. Clinical information including sex, age, depth of invasion, lymph node metastasis, TNM stage and distant metastasis was also obtained. The present study strictly followed the guidelines of the Declaration of Helsinki. All patients provided written informed consent. The study was approved by the ethics committee of General Hospital of Ningxia Medical University (approval no. 2016049).

Hematoxylin and eosin $(H \& E)$ staining. Esophageal cancer and normal tissue specimens were fixed by $4 \%$ paraformaldehyde solution at $4^{\circ} \mathrm{C}$ for $24 \mathrm{~h}$. After being embedded in paraffin, the tissues were cut into $20-\mu \mathrm{m}$ pieces. The sections were stained with $0.5 \%$ hematoxylin for $5 \mathrm{~min}$ at $37^{\circ} \mathrm{C}$ and $0.5 \%$ eosin solution for $5 \mathrm{~min}$ at $37^{\circ} \mathrm{C}$. Neutral gum was utilized for sealing and images were observed under an light microscope (Olympus Corporation) (magnification, x200).

Immunohistochemistry. Fresh tissue specimens were fixed with $4 \%$ paraformaldehyde overnight at $4{ }^{\circ} \mathrm{C}$ and dehydrated using different concentrations of alcohol. The specimen was incubated in a 1:1 mixture of $100 \%$ alcohol and xylene for $30 \mathrm{~min}$ at room temperature and then transferred to xylene for $30 \mathrm{~min}$ at $37^{\circ} \mathrm{C}$. Subsequently, the tissues were embedded in paraffin, and the tissue sections were cut to a thickness of $4 \mu \mathrm{m}$. The sections were placed in a $60^{\circ} \mathrm{C}$ incubator for $90 \mathrm{~min}$ and then quickly placed in xylene I for $15 \mathrm{~min}$ and xylene II for $15 \mathrm{~min}$ at $37^{\circ} \mathrm{C}$. Subsequently, the tissue sections were placed in absolute ethanol I, absolute ethanol II, $95,90,80,70$ and $50 \%$ ethanol for $5 \mathrm{~min}$ each at $37^{\circ} \mathrm{C}$, followed by deionized water for $5 \mathrm{~min}$. Antigen retrieval was performed using the high-pressure method (11). After washing 3 times with $1 \mathrm{X}$ PBS, the sections were incubated with $3 \%$ hydrogen peroxide at $37^{\circ} \mathrm{C}$ for $20 \mathrm{~min}$ to eliminate endogenous peroxidase activity. After washing again, the sections were blocked with 2\% BSA (Beyotime Institute of Biotechnology) at $37^{\circ} \mathrm{C}$ for $2 \mathrm{~h}$. The tissue sections were incubated with primary antibodies including anti-MCU (1:100; cat. no. sc-515930; Santa Cruz Biotechnology, Inc.), anti-VEGF (1:100; cat. no. 26381-1-AP; ProteinTech Group, Inc.), anti-Vimentin (1:150; cat. no. ab92547; Abcam), anti-E-cadherin (1:200; cat. no. ab40772; Abcam), anti-MMP2 (1:100; cat. no. 10373-2-AP; ProteinTech Group, Inc.), and anti-N-cadherin (1:100; cat. no. ab18203; Abcam) overnight at $4^{\circ} \mathrm{C}$, followed by secondary antibody $(1: 200$; cat. no. ab150077; Abcam) incubation at $37^{\circ} \mathrm{C}$ for $1 \mathrm{~h}$. The sections were stained with DAB for $5 \mathrm{~min}$ and hematoxylin for $2 \mathrm{~min}$ at $37^{\circ} \mathrm{C}$. Subsequently, the sections were placed in hydrochloric acid monoethanol for color separation for $30 \mathrm{sec}$ and turned back to blue with 1X PBS for 2 min. After dehydration and transparency, neutral gum was added to the tissue sections, followed by air drying.

Immunohistochemistry scoring assessment. Double-blind readings were performed by two experienced pathologists. The positive expression of target proteins was the appearance of brown particles on the cell membrane and/or cytoplasm. In the present study, semi-quantitative results were used to evaluate the percentage of positive cells and staining intensity, respectively (12). The number of positively stained cells was observed under 5 high-power fields using a light microscope (Olympus Corporation) (magnification, x200) on each slide, and then the percentage of positive cells was counted and scored as follows: $0,<5 \%$ Positive cells; $1,5-25 \% ; 2,26-50 \%$; 3, 51-75\%; and 4, 76-100\%. Staining intensity was scored as follows: 0, Colorless; 1, light yellow; 2, claybank; and 3, sepia. These two scores were multiplied to obtain the positive grade: 0 , Negative (-); $1-4$, weak positive $(+) ; 5-8$, positive $(++)$; and 9-12, strong positive (+++). The optical density of target proteins was measured using ImageJ software v. 1.48 (National Institutes of Health).

Western blot analysis. Tissues and cells were lysed by RIPA cell lysate (Beyotime Institute of Biotechnology) plus protease inhibitor PMSF and phosphatase inhibitor cocktail for $40 \mathrm{~min}$ on ice, followed by centrifugation at $12,000 \mathrm{x}$ g for $15 \mathrm{~min}$ at $4^{\circ} \mathrm{C}$. Subsequently, the supernatant was harvested and stored at $-80^{\circ} \mathrm{C}$. The BCA method was used to measure the total protein concentration according to the instructions of the $\mathrm{BCA}^{\mathrm{TM}}$ Protein Assay kit (Pierce; Thermo Fisher Scientific, Inc.). Protein $(30 \mu \mathrm{g})$ was loaded per lane and protein samples were separated via 12\% SDS-PAGE and then transferred to a PVDF membrane (IPVH00010; EMD Millipore). The membrane 
was blocked with $5 \%$ skimmed milk at room temperature for $2 \mathrm{~h}$ and was then incubated with primary antibodies including anti-MCU (1:500; cat. no. sc-515930; Santa Cruz Biotechnology, Inc.), anti-VEGF (1:1,000; cat. no. 26381-1-AP; ProteinTech Group, Inc.), anti-hypoxia inducible factor

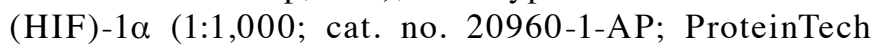
Group, Inc.) anti-Vimentin (1:2,000; cat. no. ab92547; Abcam), anti-E-cadherin $(1: 1,000$; cat. no. ab40772; Abcam), anti-MMP2 (1:1,000; cat. no. ab181286; Abcam), anti-N-cadherin (1:1,000; cat. no. ab20760; Abcam) and anti- $\beta$-actin (1:2,000; cat. no. 20536-1-AP; ProteinTech Group, Inc.) at $4^{\circ} \mathrm{C}$ overnight. After washing the membrane, the membrane was incubated with a horseradish peroxidase (HRP) secondary antibody (1:2,000; cat. no. ab7090; Abcam) at room temperature for $2 \mathrm{~h}$. The protein band was visualized using BeyoECL Plus (cat. no. KGP1121; Nanjing KeyGen Biotech Co., Ltd.). ImageJ software v.1.48 (National Institutes of Health) was used for quantifying the expression of target proteins.

Immunofluorescence. In brief, the tissue sections were incubated with unconjugated-labeled primary antibodies including anti-MCU (1:100; cat. no. sc-515930; Santa Cruz Biotechnology, Inc.), anti-E-cadherin (1:100; cat. no. ab40772; Abcam) and anti-Vimentin (1:100; cat. no. ab92547; Abcam) overnight at $4^{\circ} \mathrm{C}$, followed by Alexa Fluor ${ }^{\circledR} 488$-conjugated (1:100; cat. no. ZF-0512; OriGene Technologies, Inc.) and Alexa Fluor ${ }^{\circledR}$ 594-conjugated (1:100; cat. no. ZF-0513; OriGene Technologies, Inc.) secondary antibodies at room temperature for $2 \mathrm{~h}$. For nuclear counterstaining, cells were incubated with DAPI (1:100; cat. no. ab104139; Abcam) for $5 \mathrm{~min}$ at room temperature. The images were acquired by confocal microscopy (General Electric Company) (magnification, x200). The results were determined using ImageJ software v.1.48 (National Institutes of Health).

Cell culture. Two human esophageal cancer KYSE-150 and TE-1 cell lines (American Type Culture Collection) were cultured in RPMI-1640 medium (Gibco; Thermo Fisher Scientific Inc.) with $10 \%$ FBS (Gibco; Thermo Fisher Scientific Inc.), $100 \mathrm{U} / \mathrm{ml}$ penicillin and $100 \mathrm{U} / \mathrm{ml}$ streptomycin at $37^{\circ} \mathrm{C}$ and $5 \% \mathrm{CO}_{2}$.

Transfection. Cells were seeded onto a 6-well plate. KYSE-150 and TE-1 cells were treated with different concentrations (10, $20,30,50,70,100$ and $200 \mu \mathrm{M})$ of the MCU agonist Spermine (cat. no. 18041; Cayman Chemical Company) at $37^{\circ} \mathrm{C}$ for $48 \mathrm{~h}$. A small interfering RNA (siRNA) against MCU (si-MCU) was designed as follows: si-MCU\#1 sense, 5'-CAUAAAGGA GCCAAAAAGUCA-3' and antisense, 5'-ACUUUUUGG CUCCUUUAUGGA-3'; si-MCU\#2 sense, 5'-GGGAAUUGA CAGAGUUGCU-3' and antisense, 5'-AGCAACUCUGUC AAUUCCC-3'. Meanwhile, the sequences of the siRNA negative control (si-NC; scrambled RNA) were as follows: sense, 5'-GCCUAAGAACGACAAAUCA-3' and antisense, 5'-UGA UUUGUCGUUCUUAGGC-3'. A total of $5 \mathrm{nM}$ of si-MCU or si-NC was transfected into cells via Lipofectamine ${ }^{\circledR} 2000$ (Invitrogen; Thermo Fisher Scientific Inc.) at room temperature for $48 \mathrm{~h}$. After $48 \mathrm{~h}$, western blotting was used to examine the transfection effects.
Colony formation assay. Cells of each group were collected $24 \mathrm{~h}$ after transfection and were inoculated in $35-\mathrm{mm}$ culture dishes (500-1,000 cells/dish). These cells were incubated at $37^{\circ} \mathrm{C}$ in a $5 \% \mathrm{CO}_{2}$ incubator for 14 days. The culture medium was changed every 4-5 days. Following rinsing with IX PBS for 3 times, the cells were fixed with methanol for $10 \mathrm{~min}$ at room temperature and stained with $0.5 \%$ crystal violet for $20 \mathrm{~min}$ at room temperature. Following rinsing and drying, the colonies were photographed and counted. A total of 50 cells were considered as a colony.

Cell Counting Kit-8 (CCK-8) assay. Cells were seeded into a 96-well plate. After $48 \mathrm{~h}$ from transfection, cell viability was determined using the CCK-8 reagent (Dojindo Molecular Technologies, Inc.) for $1 \mathrm{~h}$. The absorbance at $450 \mathrm{~nm}$ was assessed utilizing a multiscan spectrum.

Transwell assay. After $24 \mathrm{~h}$ from transfection, cells were starved with serum-free RPMI-1640 medium for 6-8 $\mathrm{h}$. The digested cells were washed twice with serum-free RPMI-1640 medium and were then seeded in the upper chamber of a 24-well Transwell insert $\left(1.5 \times 10^{9}\right.$ cells/well $)$. A total of $600 \mu \mathrm{l}$ RPMI-1640 medium containing 20\% FBS was added to the lower chamber. The transfected cells were cultured at $37^{\circ} \mathrm{C}$ with $5 \% \mathrm{CO}_{2}$ for $24 \mathrm{~h}$. Afterwards, the cells were fixed using $4 \%$ paraformaldehyde for $15 \mathrm{~min}$ at $37^{\circ} \mathrm{C}$ and stained using Giemsa for $30 \mathrm{~min}$ at $37^{\circ} \mathrm{C}$. Migratory cells in lower chamber were observed under a light microscope (Olympus Corporation) (magnification, x200; scale bar $50 \mu \mathrm{m}$ ).

Statistical analysis. All statistical analysis was performed using SPSS 19.0 software (IBM Corp.) and GraphPad Prism 8.0 (GraphPad Software, Inc.). The results were expressed as the mean \pm SD from at least three independent experiments. The comparisons between two groups were analyzed using unpaired Student's t-test and one-way analysis of variance followed by Tukey's post-hoc test was performed for multiple comparisons. The association between MCU expression and clinical traits was analyzed using the $\chi^{2}$ test. Furthermore, Pearson's correlation analysis was used to analyze the correlation between MCU expression and other proteins. $\mathrm{P}<0.05$ and correlation coefficient $|r|>0.3$ were considered to indicate a statistically significant difference.

\section{Results}

MCU expression is upregulated in esophageal cancer. According to GEPIA, MCU was highly expressed in esophageal cancer, kidney renal papillary cell carcinoma, pancreatic adenocarcinoma and stomach adenocarcinoma among various types of cancer (Fig. 1A). Box plots visualized the differences in MCU expression between esophageal cancer samples $(\mathrm{n}=182)$ and normal tissues $(\mathrm{n}=286)$ from TCGA in Fig. 1B $(\mathrm{P}<0.05)$. Additionally, there was a significant difference in MCU expression among different stages of esophageal cancer (Fig. 1C). A total of 110 patients with esophageal cancer were included in the present study. Fig. 1D shows the representative images of H\&E staining results of esophageal cancer tissues and the corresponding adjacent normal tissues. Compared with normal epithelium cells of esophageal tissues, tumor cells 
A
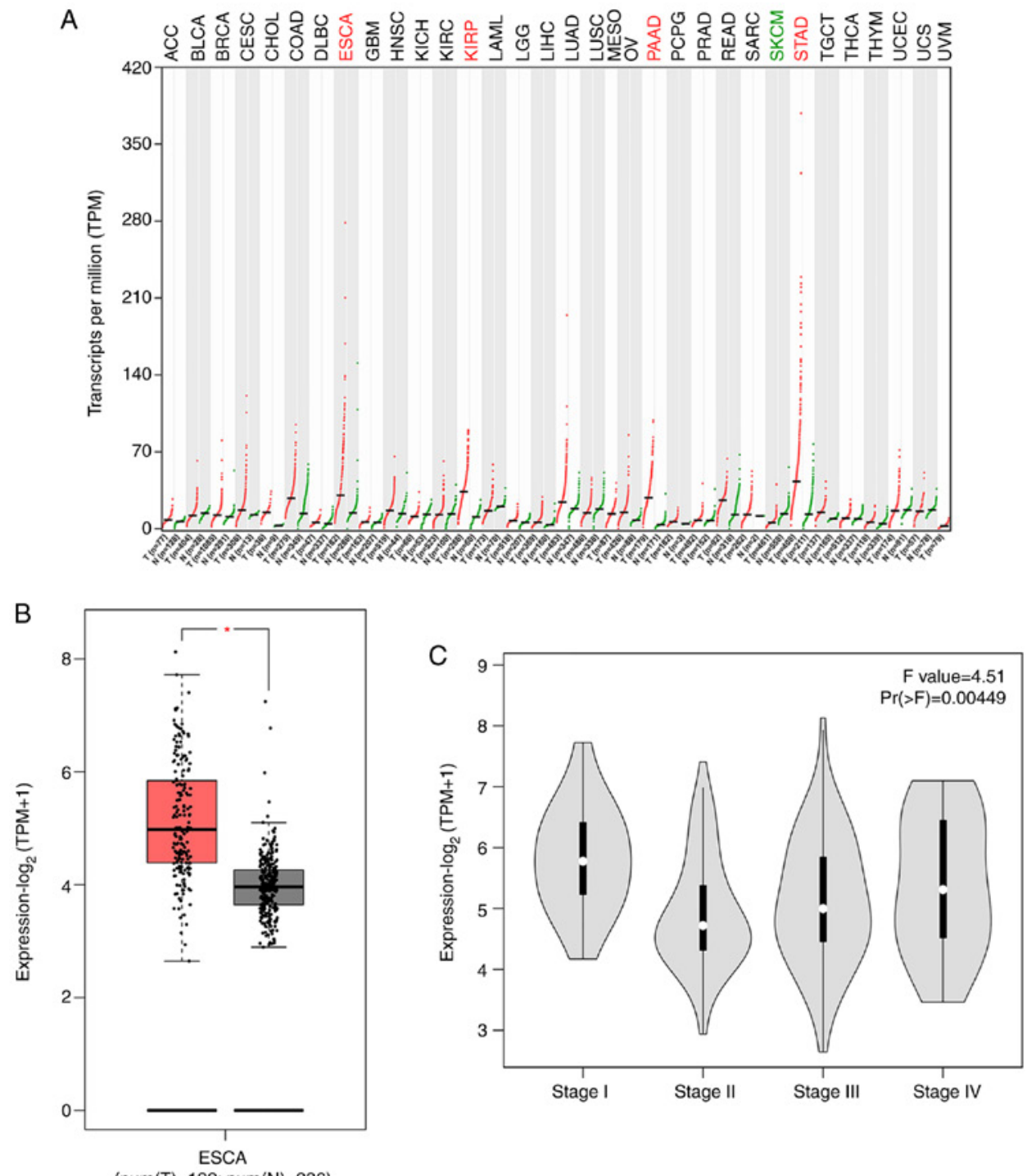

$(\operatorname{num}(\mathrm{T})=182 ; \operatorname{num}(\mathrm{N})=286$

D

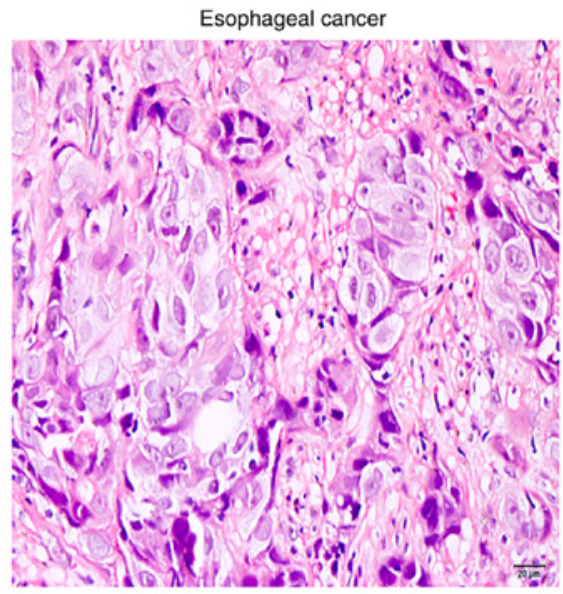

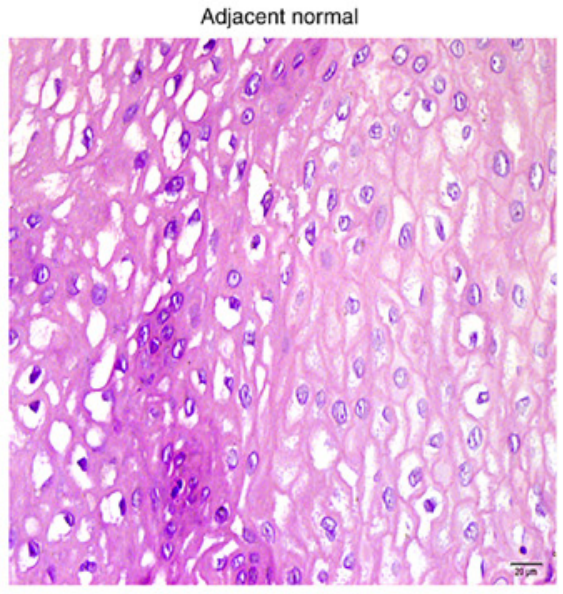

Figure 1. MCU upregulation in esophageal cancer using Gene Expression Profiling Interactive Analysis. (A) Patterns of MCU expression in various types of cancer. (B) Box plots showing the upregulation of MCU expression in esophageal cancer. " $\mathrm{P}<0.05$. (C) Violin diagram showing the difference in MCU expression among different stages of esophageal cancer. (D) Representative images of hematoxylin and eosin staining results of esophageal cancer and corresponding adjacent normal tissues. Scale bar, $20 \mu \mathrm{m}$; magnification, x200. Red represented the upregulation of MCU expression in this cancer type while green represented the downregulation of MCU expression in this cancer type. MCU, mitochondrial calcium uniporter; ACC, adrenocortical carcinoma; BLCA, bladder urothelial carcinoma; BRCA, breast invasive carcinoma; CESC, cervical squamous cell carcinoma; CHOL, cholangiocarcinoma; COAD, colon adenocarcinoma; DLBC, lymphoid neoplasm diffuse large B-cell lymphoma; ESCA, esophageal carcinoma; GBM, glioblastoma multiforme; HNSC, head and neck squamous cell carcinoma; KICH, kidney chromophobe; KIRC, kidney renal clear cell carcinoma; KIRP, kidney renal papillary cell carcinoma; LAML, acute myeloid leukemia; LGG, brain lower grade glioma; LIHC, liver hepatocellular carcinoma; LUAD, lung adenocarcinoma; LUSC, lung squamous cell carcinoma; MESO, mesothelioma; OV, ovarian serous cystadenocarcinoma; PAAD, pancreatic adenocarcinoma; PCPG, pheochromocytoma and paraganglioma; PRAD, prostate adenocarcinoma; READ, rectum adenocarcinoma; SARC, sarcoma; SKCM, skin cutaneous melanoma; STAD, stomach adenocarcinoma; TGCT, testicular germ cell tumors; THCA, thyroid carcinoma; THYM, thymoma; UCEC, uterine corpus endometrial carcinoma; UCS, uterine carcinosarcoma; UVM, uveal melanoma. 
A

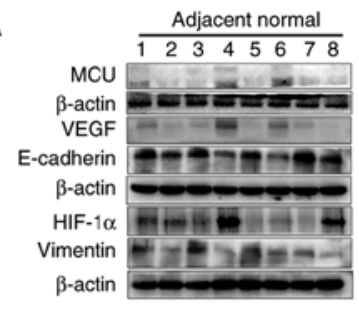

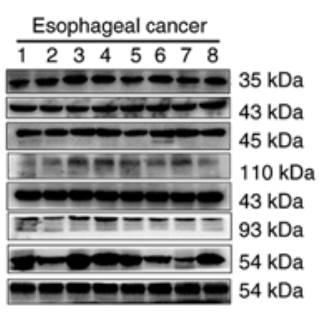

B

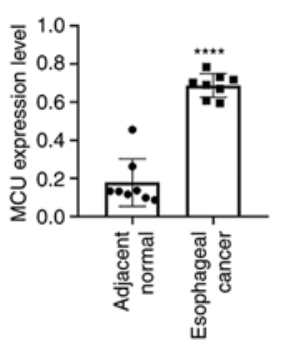

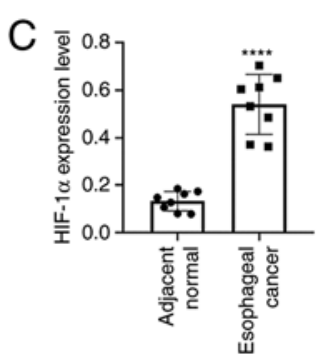

$\mathrm{D}$

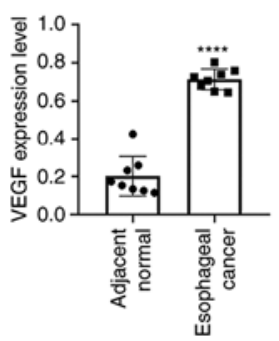

$\mathrm{H}$
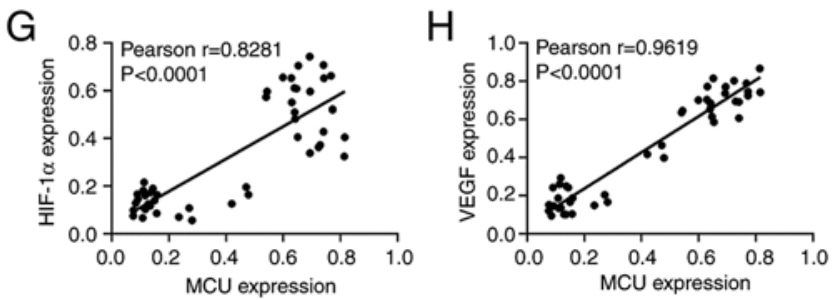
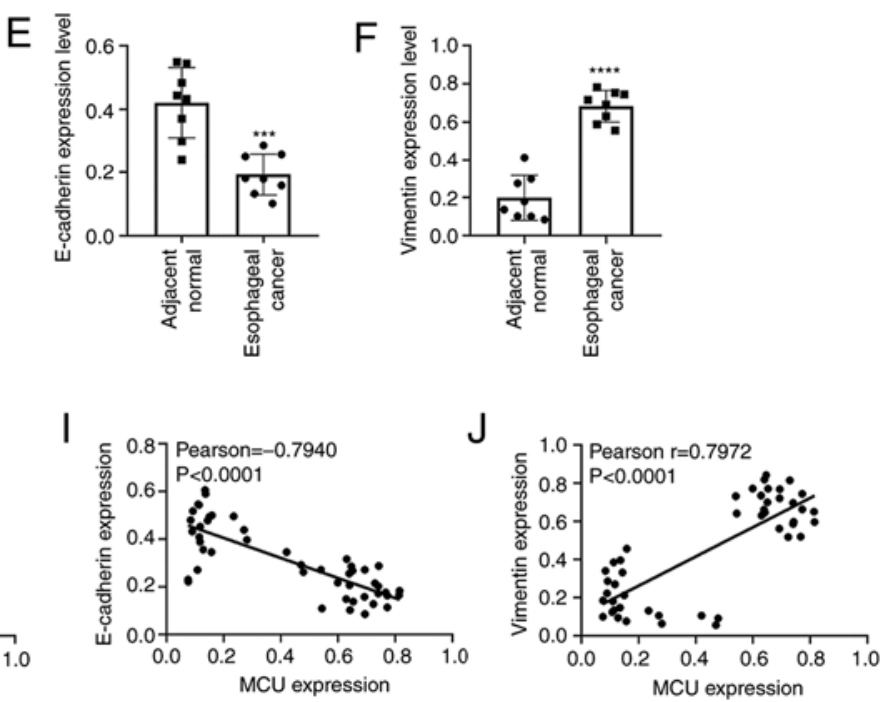

Figure 2. Western blotting results showing the protein expression levels of MCU, HIF-1 $\alpha$, VEGF, E-cadherin and Vimentin in esophageal cancer and adjacent normal tissues. (A) Representative images of western blots. Protein expression levels of (B) MCU, (C) HIF-1 $\alpha$, (D) VEGF, (E) E-cadherin and (F) Vimentin between esophageal cancer and adjacent normal tissues. Correlation between MCU and (G) HIF-1 $\alpha$, (H) VEGF, (I) E-cadherin and (J) Vimentin expression. Each experiment was repeated three times. ${ }^{* * *} \mathrm{P}<0.001$ and ${ }^{* * * * *} \mathrm{P}<0.0001$. MCU, mitochondrial calcium uniporter; HIF, hypoxia inducible factor.

had large nuclei and were in tight contact with neighbor cells. A total of 8 pairs of esophageal cancer and adjacent normal tissues were randomly selected for western blot analysis. As expected, MCU protein expression was significantly higher in esophageal cancer tissues compared with in adjacent normal tissues (Fig. 2A and B).

MCU expression is significantly correlated with $H I F-1 \alpha / V E G F / E$-cadherin/Vimentin expression in esophageal cancer. Tumor metastasis is the main cause of esophageal cancer mortality (13). Epithelial-mesenchymal transition (EMT) is associated with downregulation of E-cadherin and upregulation of vimentin expression, which contributes to tumor invasion and metastasis (14). Meanwhile, the HIF-1 $\alpha$ /VEGF signaling pathway, which can mediate the EMT process, has been considered a key target for treating cancer metastasis (14). Thus, the expression levels of HIF-1 $\alpha$, VEGF, E-cadherin and Vimentin were detected between 8 pairs of esophageal cancer tissues and adjacent normal tissues using western blotting. HIF-1 $\alpha$ (Fig. 2C) and VEGF (Fig. 2D) protein expression was significantly higher in esophageal cancer compared with in adjacent normal tissues. Additionally, low E-cadherin expression was observed in esophageal cancer tissues (Fig. 2E), while vimentin had higher expression levels in esophageal cancer than in adjacent normal tissues (Fig. 2F). Correlation analysis was then performed, revealing that there were positive correlations between $\mathrm{MCU}$ expression and HIF-1 $\alpha$ (Pearson $\mathrm{r}=0.8281$; $\mathrm{P}<0.0001$; Fig. $2 \mathrm{G}$ ) and VEGF (Pearson r=0.9619; $\mathrm{P}<0.0001$; Fig. $2 \mathrm{H}$ ) expression. Additionally, a negative correlation was observed between MCU and E-cadherin expression in esophageal cancer tissues (Pearson r=-0.7940; P<0.0001; Fig. 2I). Furthermore, MCU was positively correlated with Vimentin (Pearson $\mathrm{r}=0.7972$; $\mathrm{P}<0.0001$; Fig. 2J). Subsequently, immunofluorescence analysis of MCU, E-cadherin and Vimentin was also performed in esophageal cancer and adjacent normal tissues. Consistent with the western blot results, the immunofluorescence results revealed that MCU protein expression was significantly higher and E-cadherin protein expression was significantly lower in esophageal cancer compared with in adjacent normal tissues (Fig. 3A and B). As shown in Fig. 3C and D, both MCU and Vimentin exhibited higher expression levels in esophageal cancer than in adjacent normal tissues.

Association between MCU expression and clinicopathological features of patients with esophageal cancer. The expression and localization of MCU were detected by immunohistochemistry in 110 patients with esophageal cancer. Among 110 esophageal cancer specimens, 88 had positive expression of MCU (including weak positive, positive or strong positive expression) and others had negative expression of MCU (Table I). The association between MCU expression and clinical characteristics, including sex, age, depth of invasion, lymph node metastasis, TNM stage and distant metastasis, was analyzed. As shown in Table I, MCU expression was significantly associated with depth of invasion $(\mathrm{P}=0.031)$, 
A

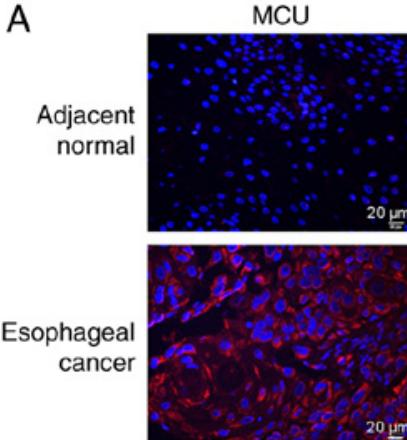

C
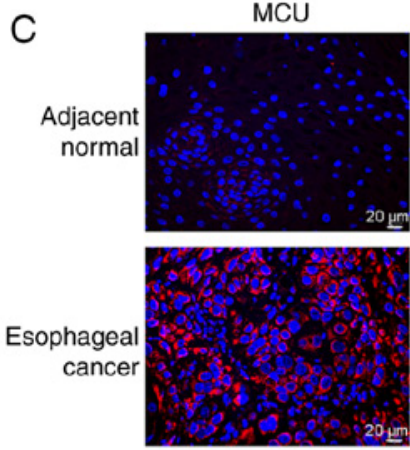

E-cadherin
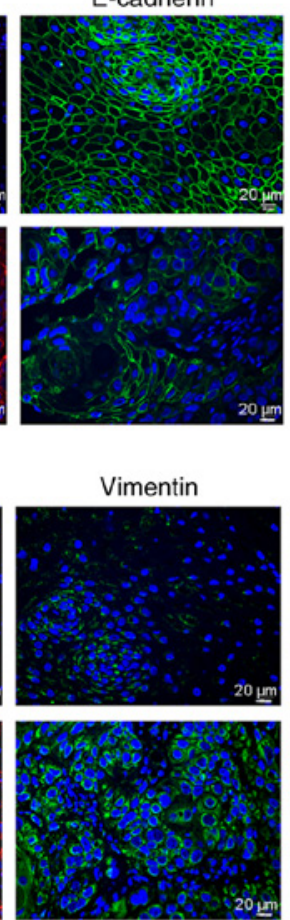

$\mathrm{MCU}+\mathrm{E}$-cadherin

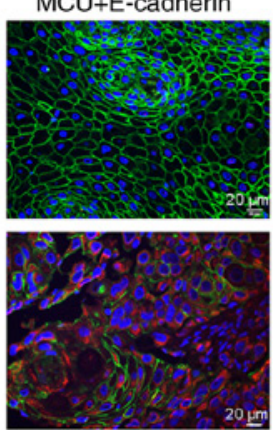

MCU+Vimentin

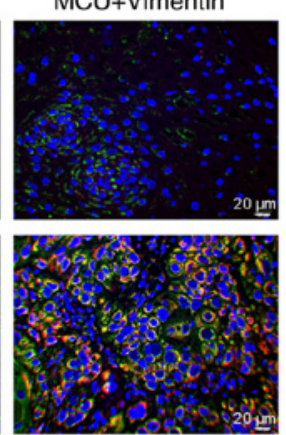

B
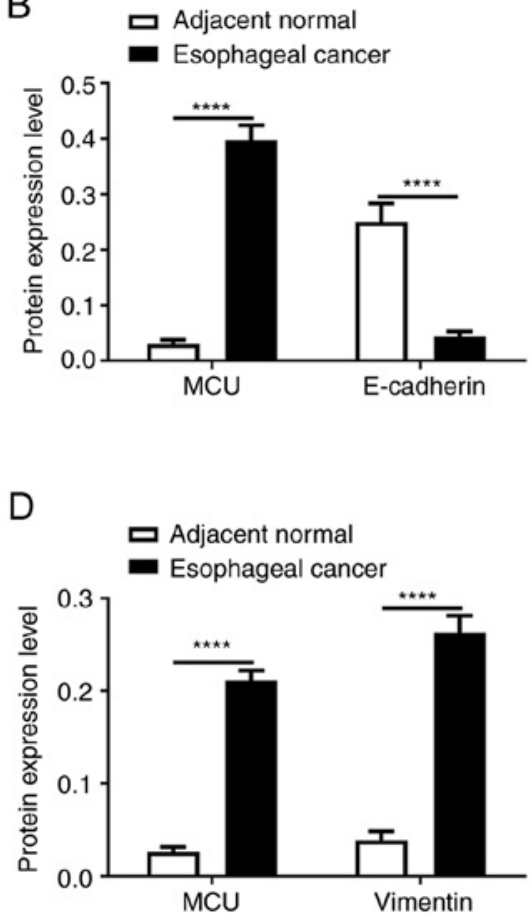

Figure 3. Immunofluorescence results of MCU, E-cadherin and Vimentin expression in esophageal cancer and adjacent normal tissues. (A) Representative images of MCU and E-cadherin expression. (B) Expression levels of MCU and E-cadherin between esophageal cancer and adjacent normal tissues. (C) Representative images of MCU and Vimentin expression. (D) Expression levels of MCU and Vimentin between esophageal cancer and adjacent normal tissues. Red represents MCU and green represents E-cadherin or Vimentin. Scale bar, $20 \mu \mathrm{m}$; magnification, $\mathrm{x} 200$. $^{* * * *} \mathrm{P}<0.0001$. MCU, mitochondrial calcium uniporter.

lymph node metastasis $(\mathrm{P}=0.027)$, TNM stage $(\mathrm{P}=0.036)$ and distant metastasis $(\mathrm{P}=0.008)$. However, there was no association between MCU expression and sex $(\mathrm{P}=0.332)$ and age $(\mathrm{P}=0.381)$ (Table I). Furthermore, $\mathrm{MCU}$ was mainly expressed in the cytoplasm. Representative results of MCU staining are shown in Fig. 4A. Significantly higher MCU expression was detected in esophageal cancer tissues compared with in adjacent normal tissues (Fig. 4B).

Immunohistochemistry results of VEGF, Vimentin, E-cadherin, MMP2 and N-cadherin in esophageal cancer. As aforementioned, MCU expression was significantly correlated with VEGF and EMT-associated proteins. Hence, the protein expression levels of VEGF, Vimentin, E-cadherin, MMP2 and N-cadherin between esophageal cancer and adjacent normal tissues were further examined by immunohistochemistry. Consistent with the aforementioned results, higher expression levels of VEGF and Vimentin were detected in esophageal cancer compared with in adjacent normal tissues (Fig. 4A and B). Furthermore, E-cadherin expression was significantly lower in esophageal cancer than in adjacent normal tissues, while MMP2 and N-cadherin protein expression was significantly upregulated in esophageal cancer tissues compared with in adjacent normal tissues (Fig. 4A and B), indicating that these proteins may be involved in the development of esophageal cancer.

MCU promotes VEGF, MMP2, Vimentin and $N$-cadherin, and inhibits E-cadherin in esophageal cancer cells. Western blotting was performed to validate the transfection effect of si-MCU in KYSE-150 and TE-1 cells. As shown in
Fig. 5A and B, MCU protein expression was significantly suppressed in KYSE-150 and TE-1 cells. After overexpression of MCU using Spermine, VEGF, Vimentin and N-cadherin expression was significantly increased in KYSE-150 cells (Fig. 5C-H). MCU overexpression did not significantly alter MMP2 expression. However, their expression levels were significantly suppressed and E-cadherin expression was significantly promoted in KYSE-150 cells after transfection with si-MCU (Fig. 5C-I). Similar results of MCU, VEGF, MMP2, Vimentin, N-cadherin and E-cadherin expression were obtained in TE-1 cells treated with Spermine or transfected with si-MCU (Fig. 5C and J-O).

MCU accelerates the proliferation and migration of esophageal cancer cells. The cellular function of MCU in esophageal cancer was further explored. CCK-8 results indicated that the viability of KYSE-150 and TE-1 cells was significantly inhibited with Spermine in a concentration-dependent manner (Fig. 6A and B). The concentration of $30 \mu \mathrm{m} / \mathrm{ml}$ Spermine was chosen as the optimal concentration for further analysis. As shown in Fig. 6C-E, MCU overexpression significantly promoted the proliferation of KYSE-150 and TE-1 cells, while opposite results were observed after transfection with si-MCU. Transwell assay results demonstrated that the migration of KYSE-150 and TE-1 cells was significantly promoted by MCU overexpression, while it was significantly suppressed after si-MCU transfection (Fig. 6F-H).

\section{Discussion}

The development of esophageal cancer is a complex process involving multiple steps and multiple factors. Despite surgical 
Table I. Association between clinicopathological parameters and MCU expression in 110 patients with esophageal cancer.

\begin{tabular}{|c|c|c|c|c|c|}
\hline \multirow[b]{2}{*}{ Clinical parameters } & \multirow[b]{2}{*}{ Total, $\mathrm{n}$} & \multicolumn{2}{|c|}{ MCU expression ${ }^{\mathrm{c}}, \mathrm{n}$} & \multirow[b]{2}{*}{$\chi^{2}$} & \multirow[b]{2}{*}{ P-value } \\
\hline & & Positive $(n=88)$ & Negative $(n=22)$ & & \\
\hline \multicolumn{6}{|l|}{$\operatorname{Sex}$} \\
\hline Male & 65 & 54 & 11 & \multirow[t]{2}{*}{0.940} & \multirow[t]{2}{*}{0.332} \\
\hline Female & 45 & 34 & 11 & & \\
\hline \multicolumn{6}{|l|}{ Age, years } \\
\hline$<60$ & 66 & 51 & 15 & \multirow[t]{2}{*}{0.767} & \multirow[t]{2}{*}{0.381} \\
\hline$\geq 60$ & 44 & 37 & 7 & & \\
\hline \multicolumn{6}{|l|}{ Depth of invasion } \\
\hline $\mathrm{T} 1 / \mathrm{T} 2$ & 42 & 38 & 4 & \multirow[t]{2}{*}{4.660} & \multirow[t]{2}{*}{$0.031^{\mathrm{a}}$} \\
\hline $\mathrm{T} 3 / \mathrm{T} 4$ & 68 & 50 & 18 & & \\
\hline \multicolumn{6}{|c|}{ Lymph node metastasis } \\
\hline N0 & 38 & 26 & 12 & \multirow[t]{2}{*}{4.865} & \multirow[t]{2}{*}{$0.027^{\mathrm{a}}$} \\
\hline $\mathrm{N} 1 / \mathrm{N} 2 / \mathrm{N} 3$ & 72 & 62 & 10 & & \\
\hline \multicolumn{6}{|l|}{ TNM stage } \\
\hline I-II & 39 & 27 & 12 & \multirow[t]{2}{*}{4.380} & \multirow[t]{2}{*}{$0.036^{\mathrm{a}}$} \\
\hline III-IV & 71 & 61 & 10 & & \\
\hline \multicolumn{6}{|l|}{ Distant metastasis } \\
\hline Absent & 43 & 29 & 14 & \multirow[t]{2}{*}{6.959} & \multirow[t]{2}{*}{$0.008^{\mathrm{b}}$} \\
\hline Present & 67 & 59 & 8 & & \\
\hline
\end{tabular}

${ }^{\mathrm{a}} \mathrm{P}<0.05$ and ${ }^{\mathrm{b}} \mathrm{P}<0.01 .{ }^{\mathrm{c}} \mathrm{Patients}$ were divided into positive and negative expression groups, where the positive expression group included weak positive, positive and strong positive expression. MCU, mitochondrial calcium uniporter.
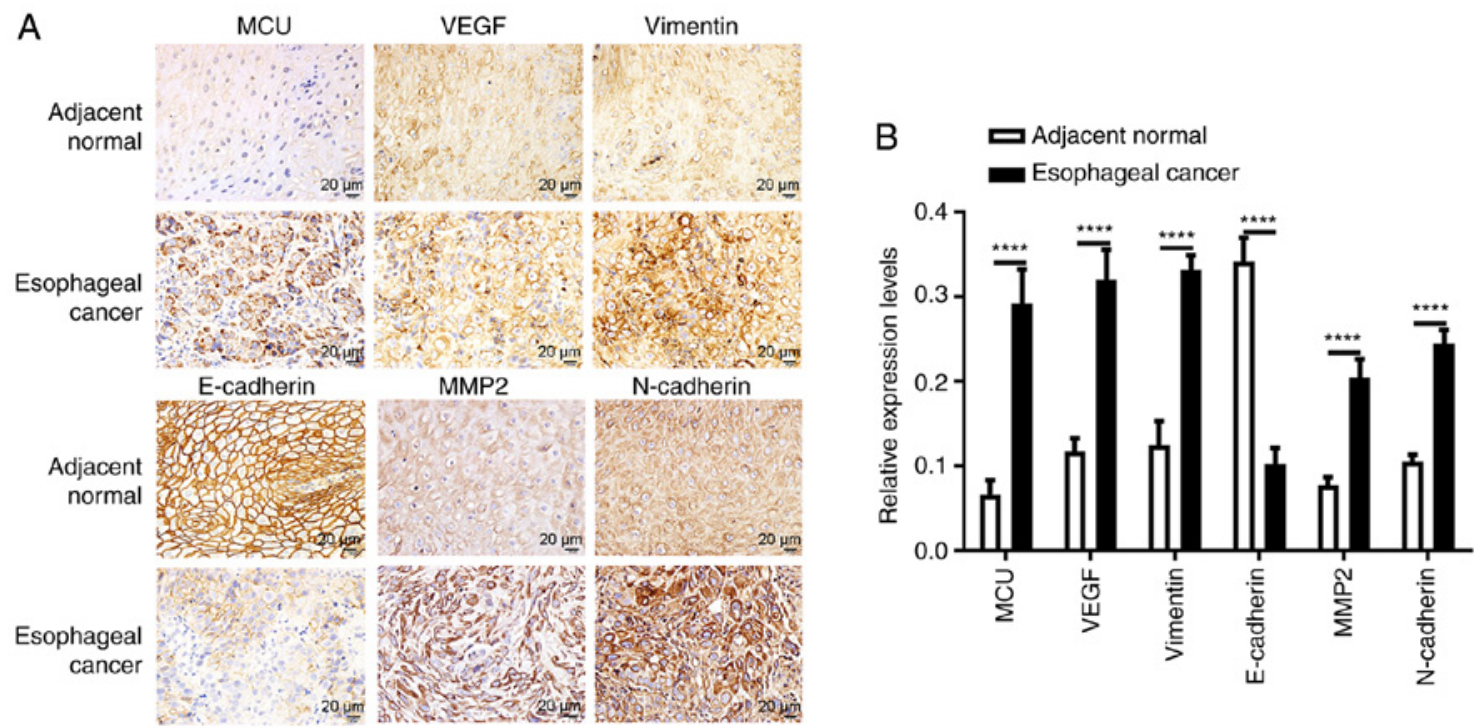

Figure 4. Immunohistochemistry results of MCU, VEGF, Vimentin, E-cadherin, MMP2 and N-cadherin in esophageal cancer and adjacent normal tissues. (A) Representative images of immunohistochemistry results. (B) Expression levels of MCU, VEGF, Vimentin, E-cadherin, MMP2 and N-cadherin between esophageal cancer and adjacent normal tissues. Scale bar, $20 \mu \mathrm{m}$; magnification, $\mathrm{x} 200$. $^{* * * *} \mathrm{P}<0.0001$. MCU, mitochondrial calcium uniporter.

resection and other novel treatments, patients with esophageal cancer are usually diagnosed in the middle and late stages, leading to a high mortality and poor prognosis (15). Moreover, lymph node metastasis is an important event for esophageal cancer, since it may contribute to a high recurrence rate $(16,17)$. The present study identified that MCU was significantly highly expressed in esophageal cancer. Its high expression promoted the proliferation, migration and EMT of esophageal cancer cells. Thus, high MCU expression may contribute to esophageal cancer metastasis.

The present study analyzed MCU expression in patients with esophageal cancer by western blotting, immunohistochemistry 
A

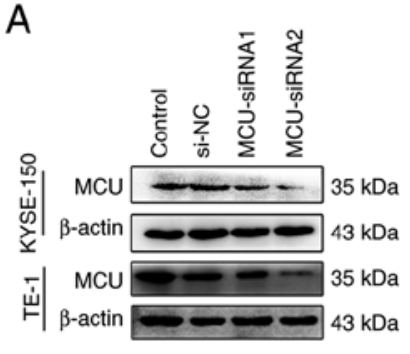

D

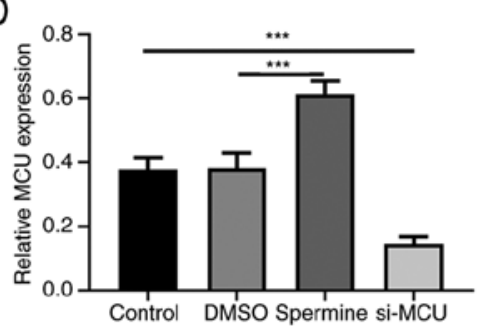

G

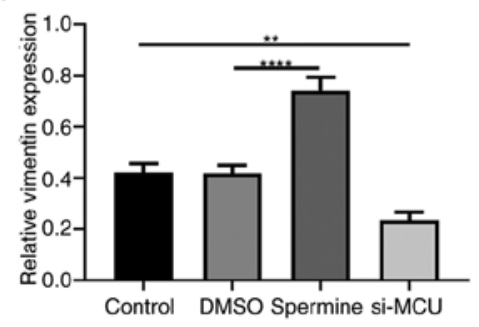

$J$

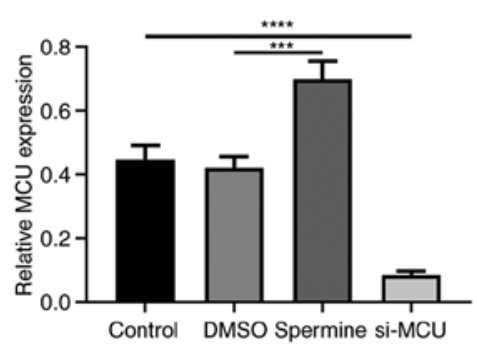

M

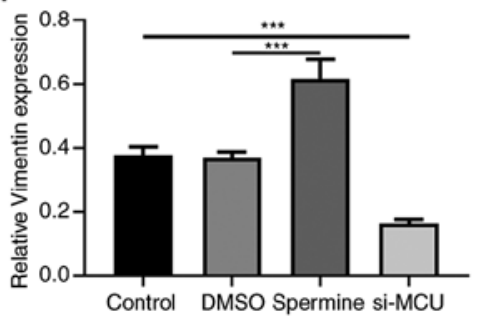

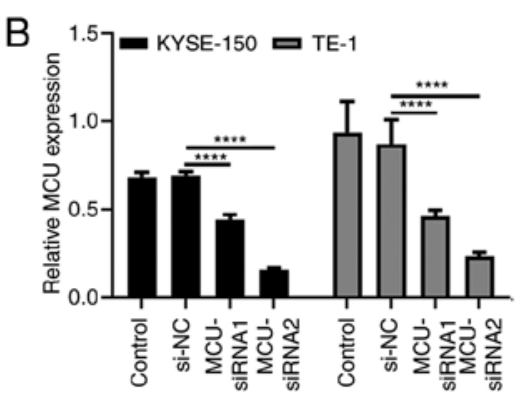

E

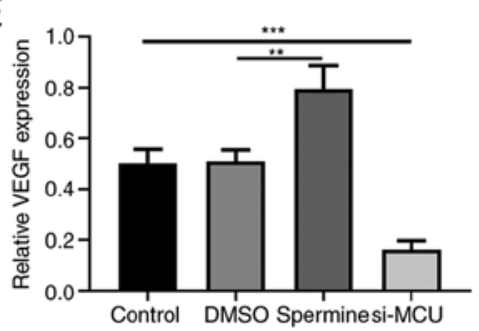

$\mathrm{H}$

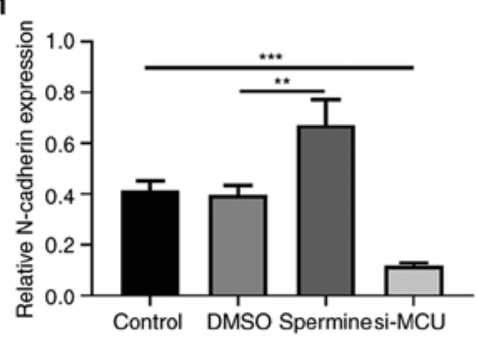

$\mathrm{K}$

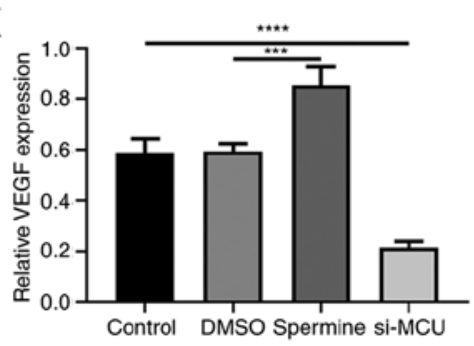

$\mathrm{N}$

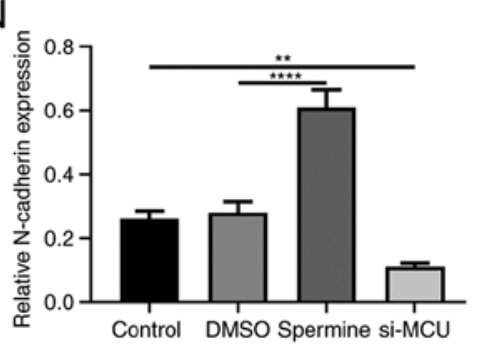

C

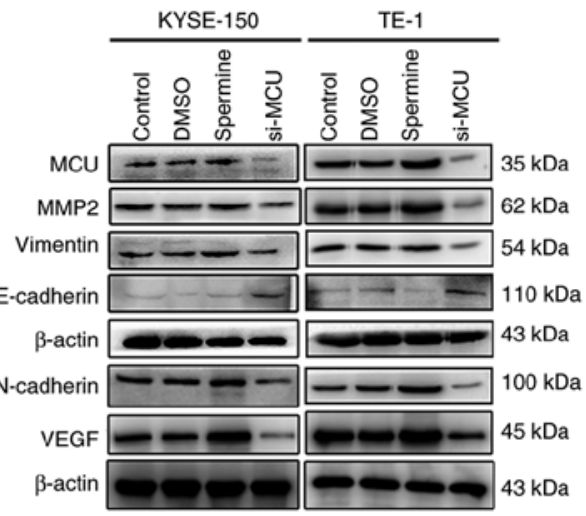

$\mathrm{F}$

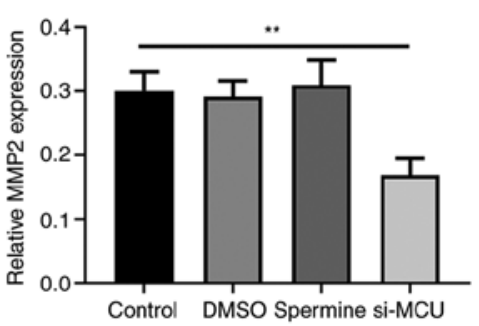

।

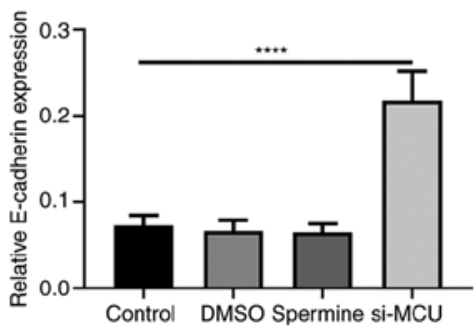

$\mathrm{L}$

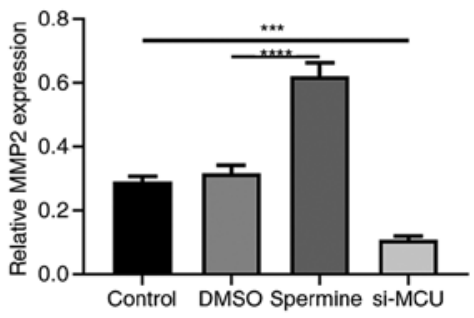

O

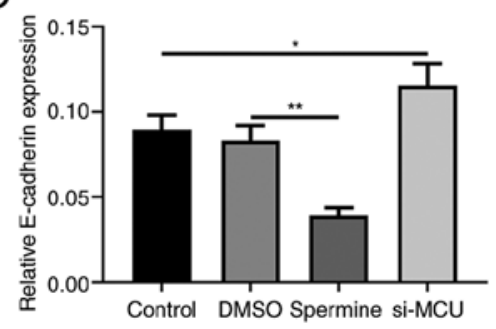

Figure 5. MCU promotes VEGF, MMP2, Vimentin and N-cadherin expression, and inhibits E-cadherin expression in esophageal cancer cells. (A and B) Western blotting was used to validate the effect of si-MCU transfection in KYSE-150 and TE-1 cells. (C) Representative images of western blotting for the protein expression levels of VEGF, MMP2, Vimentin, N-cadherin and E-cadherin in KYSE-150 and TE-1 cells treated with Spermine or transfected with si-MCU. Quantification of protein expression levels of (D) MCU, (E) VEGF, (F) MMP2, (G) Vimentin, (H) N-cadherin and (I) E-cadherin in KYSE-150 cells treated with Spermine or si-MCU. Quantification of protein expression levels of (J) MCU, (K) VEGF, (L) MMP2, (M) Vimentin, (N) N-cadherin and (O) E-cadherin in TE-1 cells treated with Spermine or si-MCU. $\beta$-actin was used as a reference control. ${ }^{*} \mathrm{P}<0.05 ;{ }^{* *} \mathrm{P}<0.01 ;{ }^{* * *} \mathrm{P}<0.001 ;{ }^{* * * * *} \mathrm{P}<0.0001$. MCU, mitochondrial calcium uniporter; si/siRNA, small interfering RNA; NC, negative control.

and immunofluorescence. Moreover, the association between MCU expression and clinical characteristics was analyzed. The current data suggested that MCU expression was higher in esophageal cancer tissues compared with normal tissues. In 110 cases, there were significant associations between MCU expression and TNM stage and lymph node metastasis. It 
A
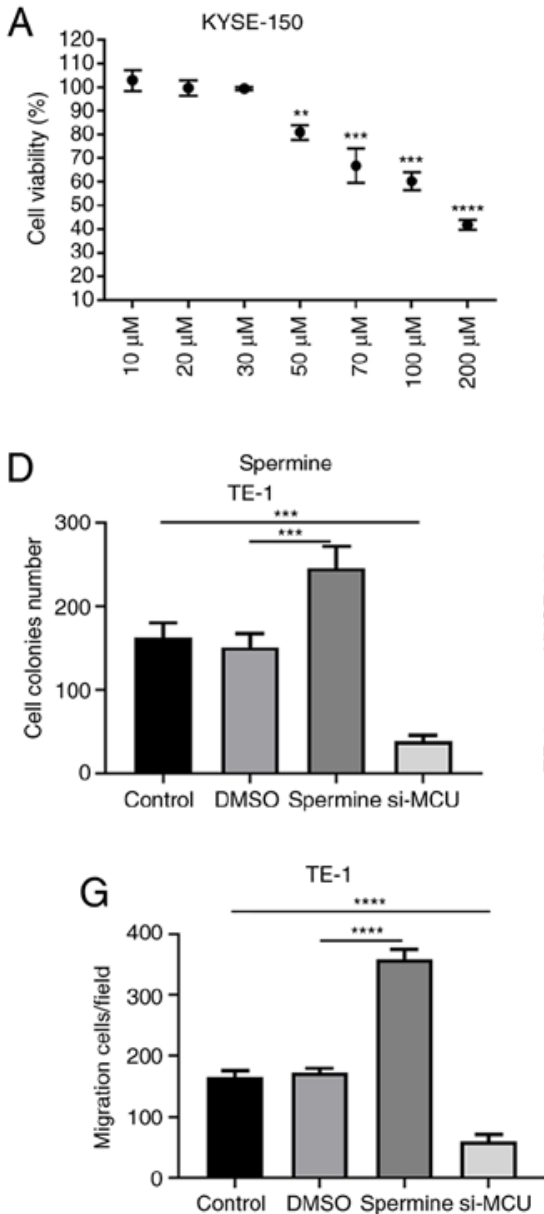

B

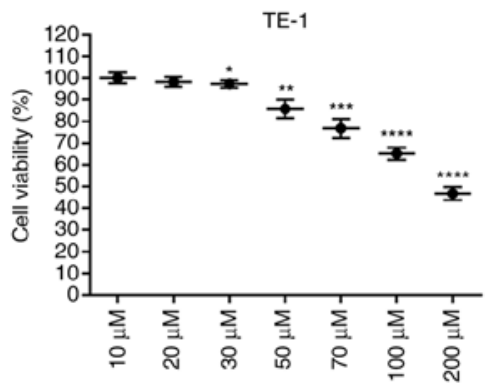

E

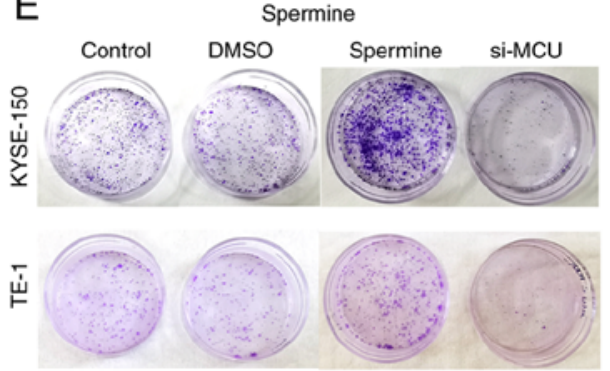

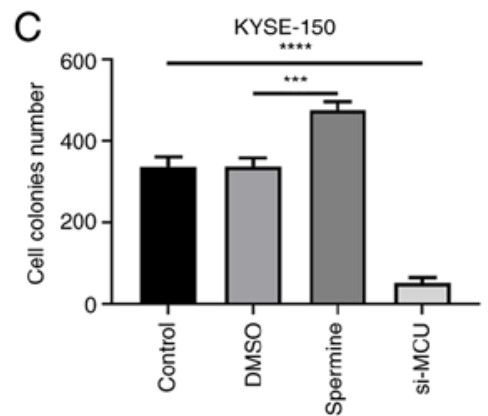

F

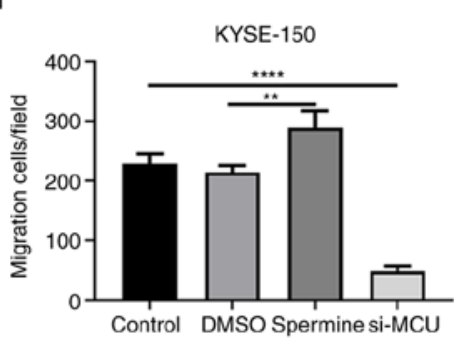

$\mathrm{H}$
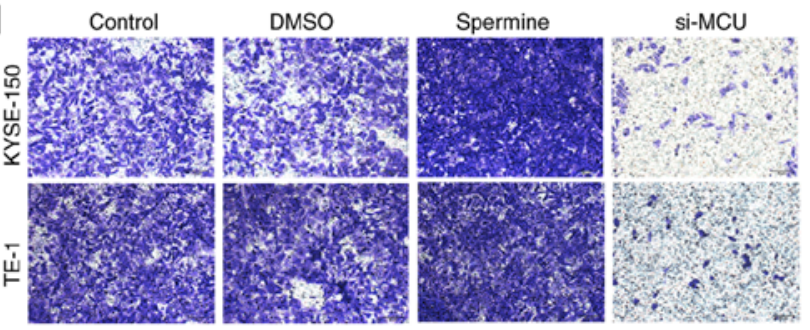

Figure 6. MCU accelerates the proliferation and migration of esophageal cancer cells. Cell viability was detected in (A) KYSE-150 and (B) TE-1 cells treated with different concentrations of Spermine using Cell Counting Kit- 8 assay. Colony formation assay was used to examine the proliferative capacity of KYSE-150 and TE-1 cells treated with Spermine or si-MCU. The number of (C) KYSE-150 and (D) TE-1 cell colonies was quantified, and (E) representative images of colony formation assay. Transwell assay was performed to assess the migratory ability of KYSE-150 and TE-1 cells after treatment with Spermine or si-MCU. The number of migrated (F) KYSE-150 and (G) TE-1 cells was quantified, and (H) representative images of Transwell assay. Magnification, x200 and scale bar, $50 \mu \mathrm{m}$. ${ }^{*} \mathrm{P}<0.05 ;{ }^{* *} \mathrm{P}<0.01 ;{ }^{* * *} \mathrm{P}<0.001 ;{ }^{* * * *} \mathrm{P}<0.0001$. MCU, mitochondrial calcium uniporter; si, small interfering RNA.

has been identified that the prognosis of esophageal cancer is greatly affected by lymph node metastasis, which is associated with poor survival (18). The current results indicated that high MCU expression was associated with the invasiveness of esophageal cancer, thereby serving an important role in the metastasis of esophageal cancer.

According to the present western blotting results, MCU expression was significantly correlated with HIF-1 $\alpha$ and VEGF expression, and with the EMT process in esophageal cancer. In the present study, a positive correlation was identified between MCU and HIF-1 $\alpha$ expression. Similar results were observed in breast cancer tissues (7). Furthermore, silencing MCU can inhibit HIF-1 $\alpha$ expression in colon cancer and triple-negative breast cancer $(7,19)$. These findings indicated that HIF-1 $\alpha$ may be regulated by MCU. In the current study, it was revealed that MCU promoted VEGF, MMP2, Vimentin and N-cadherin expression, and inhibited E-cadherin expression in esophageal cancer cells. However, further studies need to be performed. Tumor metastasis is the main cause of death for most patients with esophageal cancer (20). HIF-1 $\alpha$ activation is one of the most important mechanisms that promotes metastasis and increases tumor aggressiveness (21-23). Additionally, high VEGF expression was found in esophageal cancer tissues, which may serve a major angiogenic role in esophageal cancer. Several meta-analysis studies have revealed that high VEGF expression is associated with poor overall survival in patients with esophageal cancer $(24,25)$. Furthermore, it has been confirmed that VEGF is a downstream target of HIF-1 $\alpha$ in esophageal cancer (26). EMT is one of the main mechanisms for inducing tumor invasion and metastasis $(27,28)$. EMT is a process in which epithelial cells lose their polarity and acquire a mesenchymal phenotype $(24,25)$. Hypoxia induced by HIF-1 $\alpha$ is an important microenvironment factor that can induce the expression of certain EMT regulators and coordinate the interaction between these EMT regulators (such as E-cadherin and Vimentin) (29-31). The extracellular matrix serves an important role in the development of esophageal cancer (32). It has been shown that certain molecules are involved in these events, especially different collagen isoforms and enzymes associated with their metabolism, such as MMPs (32). Different MMP isoforms, especially MMP-2, $-3,-7$ and -9 , have been reported to be involved in the development of esophageal cancer (32). The invasion and metastasis of esophageal cancer cells involve complex, continuous multi-step processes. Previous studies have revealed that there is a close association between MMP2 and the invasion and metastasis of esophageal cancer cells (33-35). High 
MMP2 expression was observed in esophageal cancer tissue samples in the present study. Additionally, it has been found that MCU promotes the activity of MMP2 and cell movement, thereby promoting invasion, migration and metastasis of liver cancer cells (8).

Metastasis is one of the most important causes of death among patients with esophageal cancer and one of the important malignant phenotypes of cancer (13). Patients with esophageal cancer are prone to metastases to the lungs, brain and kidneys (36). The ability of cancer cells to invade and migrate is the basis of cancer metastasis. Strong invasive and migratory abilities help to break through the basement membrane and enter the lymphatic system or blood vessels, which eventually lead to the metastasis to lymph nodes or distant organs (13). The present results suggested that MCU accelerated proliferation and migration of esophageal cancer cells.

However, there were several limitations in the current study. Firstly, this was a retrospective study conducted at a single institution, with a relatively small sample size. The present results need to be further confirmed based on larger sample multi-center analysis. Secondly, the exact mechanism of esophageal cancer metastasis caused by MCU dysregulation is unclear and requires further study. In conclusion, the current data indicated that MCU was frequently expressed in esophageal cancer. Further research is required to confirm the application of MCU in the diagnosis and treatment of esophageal cancer.

Overall, the present study described for the first time the abnormal expression levels of MCU and its potential clinical value in esophageal cancer, providing a new potential biomarker and therapeutic target for esophageal cancer. However, the role of MCU in esophageal cancer requires further study.

\section{Acknowledgements}

Not applicable.

\section{Funding}

The present study was funded by Project of Hebei Medical Science Research Project (grant no. 20191127); Ningxia Medical University School-level Project (grant no. XM2019072); Natural Science Foundation of Ningxia ( grant no. 2021AAC03343) and Ningxia Hui Autonomous Region Key R\&D Projects (grant no. 2020BEG03001).

\section{Availability of data and materials}

The datasets used and/or analyzed during the current study are available from the corresponding author on reasonable request.

\section{Authors' contributions}

FZ conceived and designed the study. YM, XW, YL and WL conducted most of the experiments and data analysis, and wrote the manuscript. YH, HY and RH conducted immunohistochemistry and immunofluorescence experiments and data analysis and wrote and revised the manuscript. FZ and
YM confirmed the authenticity of all the raw data. All authors reviewed and approved the final manuscript.

\section{Ethics approval and consent to participate}

The study was approved by the Ethics Committee of General Hospital of Ningxia Medical University (Yinchuan, China; approval no. 2016049). All patients provided written informed consent.

\section{Patient consent for publication}

Not applicable.

\section{Competing interests}

The authors declare that they have no competing interests.

\section{References}

1. Siegel RL, Miller KD and Jemal A: Cancer statistics, 2019. CA Cancer J Clin 69: 7-34, 2019.

2. Cai R, Wang P, Zhao X, Lu X, Deng R, Wang X, Su Z, Hong C and Lin J: LTBP1 promotes esophageal squamous cell carcinoma progression through epithelial-mesenchymal transition and cancer-associated fibroblasts transformation. J Transl Med 18: $139,2020$.

3. Xi M, Yang Y, Zhang L, Yang H, Merrell KW, Hallemeier CL, Shen RK, Haddock MG, Hofstetter WL, Maru DM, et al: Multi-institutional analysis of recurrence and survival after neoadjuvant chemoradiotherapy of esophageal cancer: Impact of histology on recurrence patterns and outcomes. Ann Surg 269: 663-670, 2019.

4. Baughman JM, Perocchi F, Girgis HS, Plovanich M, Belcher-Timme CA, Sancak Y, Bao XR, Strittmatter L, Goldberger O, Bogorad RL, et al: Integrative genomics identifies MCU as an essential component of the mitochondrial calcium uniporter. Nature 476: 341-345, 2011.

5. Vultur A, Gibhardt CS, Stanisz H and Bogeski I: The role of the mitochondrial calcium uniporter (MCU) complex in cancer. Pflugers Arch 470: 1149-1163, 2018.

6. Hall DD, Wu Y, Domann FE, Spitz DR and Anderson ME: Mitochondrial calcium uniporter activity is dispensable for MDA-MB-231 breast carcinoma cell survival. PLoS One 9: e96866, 2014

7. Tosatto A, Sommaggio R, Kummerow C, Bentham RB, Blacker TS, Berecz T, Duchen MR, Rosato A, Bogeski I, Szabadkai G, et al: The mitochondrial calcium uniporter regulates breast cancer progression via HIF-1 $\alpha$. EMBO Mol Med 8: 569-585, 2016.

8. Ren T, Zhang H, Wang J, Zhu J, Jin M, Wu Y, Guo X, Ji L, Huang Q, Zhang $\mathrm{H}$, et al: MCU-dependent mitochondrial $\mathrm{Ca}^{2+}$ inhibits $\mathrm{NAD}(+) / \mathrm{SIRT} 3 / \mathrm{SOD} 2$ pathway to promote ROS production and metastasis of HCC cells. Oncogene 36: 5897-5909, 2017.

9. Chen L, Sun Q, Zhou D, Song W, Yang Q, Ju B, Zhang L, Xie H, Zhou L, Hu Z, et al: HINT2 triggers mitochondrial $\mathrm{Ca}^{2+}$ influx by regulating the mitochondrial $\mathrm{Ca}^{2+}$ uniporter (MCU) complex and enhances gemcitabine apoptotic effect in pancreatic cancer. Cancer Lett 411: 106-116, 2017.

10. Koval OM, Nguyen EK, Santhana V, Fidler TP, Sebag SC, Rasmussen TP, Mittauer DJ, Strack S, Goswami PC, Abel ED and Grumbach IM: Loss of MCU prevents mitochondrial fusion in G1-S phase and blocks cell cycle progression and proliferation. Sci Signal 12: eaav1439, 2019.

11. Sawaguchi A, McDonald KL and Forte JG: High-pressure freezing of isolated gastric glands provides new insight into the fine structure and subcellular localization of $\mathrm{H}+\mathrm{K}+$-ATPase in gastric parietal cells. J Histochem Cytochem 52: 77-86, 2004.

12. Hsieh CC, Hsu HS, Li AF and Chen YJ: Clinical relevance of PD-L1 and PD-L2 overexpression in patients with esophageal squamous cell carcinoma. J Thorac Dis 10: 4433-4444, 2018.

13. Yang W, Han Y, Zhao X, Duan L, Zhou W, Wang X, Shi G, Che Y, Zhang Y, Liu J, et al: Advances in prognostic biomarkers for esophageal cancer. Expert Rev Mol Diagn 19: 109-119, 2019. 
14. Li C, Wang Q, Shen S, Wei X and Li G: HIF-1 $\alpha /$ VEGF signaling-mediated epithelial-mesenchymal transition and angiogenesis is critically involved in anti-metastasis effect of luteolin in melanoma cells. Phytother Res 33: 798-807, 2019.

15. Okadome K, Baba Y, Yagi T, Kiyozumi Y, Ishimoto T, Iwatsuki M, Miyamoto Y, Yoshida N, Watanabe M and Baba H: Prognostic nutritional index, tumor-infiltrating lymphocytes, and prognosis in patients with esophageal cancer. Ann Surg 271: 693-700, 2020.

16. Dubecz A, Kern M, Solymosi N, Schweigert M and Stein HJ: Predictors of lymph node metastasis in surgically resected T1 esophageal cancer. Ann Thorac Surg 99: 1879-1886, 2015.

17. Qu J, Shen C, Qin J, Wang Z, Liu Z, Guo J, Zhang H, Gao P, Bei T, Wang Y, et al: The MR radiomic signature can predict preoperative lymph node metastasis in patients with esophageal cancer. Eur Radiol 29: 906-914, 2019.

18. Al-Kaabi A, van der Post RS, Huising J, Rosman C, Nagtegaal ID and Siersema PD: Predicting lymph node metastases with endoscopic resection in cT2N0M0 oesophageal cancer: A systematic review and meta-analysis. United European Gastroenterol J 8: 35-43, 2020.

19. Sun Y, Li M, Liu G, Zhang X, Zhi L, Zhao J and Wang G: The function of Piezol in colon cancer metastasis and its potential regulatory mechanism. J Cancer Res Clin Oncol 146: 1139-1152, 2020.

20. Zhang J, Luo A, Huang F, Gong T and Liu Z: SERPINE2 promotes esophageal squamous cell carcinoma metastasis by activating BMP4. Cancer Lett 469: 390-398, 2020.

21. Hu X, Lin J, Jiang M, He X, Wang K, Wang W, Hu C, Shen Z, He Z, Lin $\mathrm{H}$, et al: HIF-1 $\alpha$ promotes the metastasis of esophageal squamous cell carcinoma by targeting SP1. J Cancer 11: 229-240, 2020.

22. Tang NN, Zhu H, Zhang HJ, Zhang WF, Jin HL, Wang L, Wang P, He GJ, Hao B and Shi RH: HIF-1 $\alpha$ induces VE-cadherin expression and modulates vasculogenic mimicry in esophageal carcinoma cells. World J Gastroenterol 20: 17894-17904, 2014

23. Zhu Y, Zang Y, Zhao F, Li Z, Zhang J, Fang L, Li M, Xing L, $\mathrm{Xu} \mathrm{Z}$ and $\mathrm{Yu} \mathrm{J}$ : Inhibition of HIF-1alpha by PX-478 suppresses tumor growth of esophageal squamous cell cancer in vitro and in vivo. Am J Cancer Res 7: 1198-1212, 2017.

24. Chen M, Cai E, Huang J, Yu P and Li K: Prognostic value of vascular endothelial growth factor expression in patients with esophageal cancer: A systematic review and meta-analysis. Cancer Epidemiol Biomarkers Prev 21: 1126-1134, 2012.

25. Peng J, Shao N, Peng H and Chen LQ: Prognostic significance of vascular endothelial growth factor expression in esophageal carcinoma: A meta-analysis. J Buon 18: 398-406, 2013.

26. Li B, Xu WW, Han L, Chan KT, Tsao SW, Lee NPY, Law S, Xu LY, Li EM, Chan KW, et al: MicroRNA-377 suppresses initiation and progression of esophageal cancer by inhibiting CD133 and VEGF. Oncogene 36: 3986-4000, 2017.
27. Qin T, Liu W, Huo J, Li L, Zhang X, Shi X, Zhou J and Wang C: SIRT1 expression regulates the transformation of resistant esophageal cancer cells via the epithelial-mesenchymal transition. Biomed Pharmacother 103: 308-316, 2018.

28. Taniguchi D, Saeki H, Nakashima Y, Kudou K, Nakanishi R, Kubo N, Ando K, Oki E, Oda Y and Maehara Y: CD44v9 is associated with epithelial-mesenchymal transition and poor outcomes in esophageal squamous cell carcinoma. Cancer Med 7: 6258-6268, 2018.

29. Nahomi RB and Nagaraj RH: The role of HIF-1 $\alpha$ in the TGF- 32 -mediated epithelial-to-mesenchymal transition of human lens epithelial cells. J Cell Biochem 119: 6814-6827, 2018.

30. Yeh YH, Hsiao HF, Yeh YC, Chen TW and Li TK: Inflammatory interferon activates HIF-1 $\alpha$-mediated epithelial-to-mesenchymal transition via PI3K/AKT/mTOR pathway. J Exp Clin Cancer Res 37: 70, 2018.

31. Zhang J, Zhang Q, Lou Y, Fu Q, Chen Q, Wei T, Yang J, Tang J, Wang J, Chen Y, et al: Hypoxia-inducible factor-1alpha/interleukin-1beta signaling enhances hepatoma epithelial-mesenchymal transition through macrophages in a hypoxic-inflammatory microenvironment. Hepatology 67: 1872-1889, 2018.

32. Palumbo A Jr, Meireles Da Costa N, Pontes B, Leite de Oliveira F, Lohan Codeço M, Ribeiro Pinto LF and Nasciutti LE: Esophageal cancer development: crucial clues arising from the extracellular matrix. Cells 9: 455, 2020.

33. Uraoka N, Oue N, Sakamoto N, Sentani K, Oo HZ, Naito Y, Noguchi T and Yasui W: NRD1, which encodes nardilysin protein, promotes esophageal cancer cell invasion through induction of MMP2 and MMP3 expression. Cancer Sci 105: 134-140, 2014.

34. Li L, Yue GG, Lee JK, Wong EC, Fung KP, Yu J, Lau CB and Chiu PW: The adjuvant value of Andrographis paniculata in metastatic esophageal cancer treatment-from preclinical perspectives. Sci Rep 7: 854, 2017.

35. Xuan X, Li S, Lou X, Zheng X, Li Y, Wang F, Gao Y, Zhang H, $\mathrm{He} \mathrm{H}$ and Zeng Q: Stat3 promotes invasion of esophageal squamous cell carcinoma through up-regulation of MMP2. Mol Biol Rep 42: 907-915, 2015.

36. Kromer C, Xu J, Ostrom QT, Gittleman H, Kruchko C, Sawaya R and Barnholtz-Sloan JS: Estimating the annual frequency of synchronous brain metastasis in the United States 2010-2013: A population-based study. J Neurooncol 134: 55-64, 2017.

This work is licensed under a Creative Commons

Attribution-NonCommercial-NoDerivatives 4.0 International (CC BY-NC-ND 4.0) License. 